\title{
Visceral fat obesity is the key risk factor for the development of reflux erosive esophagitis in 40-69-years subjects
}

\author{
Shinya Ohashi ${ }^{1,2}$ (1) $\cdot$ Takahisa Maruno $^{1,3} \cdot$ Keita Fukuyama $^{2,4} \cdot$ Osamu Kikuchi $^{2} \cdot$ Tomohiko Sunami $^{2} \cdot$ Yuki Kondo $^{2}$. \\ Seiichiro Imai $^{1}$ - Aki Matsushima ${ }^{1} \cdot$ Kazuyo Suzuki $^{1}$ - Fumika Usui ${ }^{1} \cdot$ Masahiro Yakami $^{1} \cdot$ Atsushi Yamada $^{2}$. \\ Hiroyoshi Isoda ${ }^{1} \cdot$ Shigemi Matsumoto $^{2,4} \cdot$ Hiroshi Seno $^{3} \cdot$ Manabu Muto $^{2} \cdot$ Mayumi Inoue $^{1}$
}

Received: 2 March 2021 / Accepted: 7 June 2021 / Published online: 12 June 2021

(c) The Author(s) 2021

\begin{abstract}
Background Visceral fat obesity can be defined quantitatively by abdominal computed tomography, however, the usefulness of measuring visceral fat area to assess the etiology of gastrointestinal reflux disease has not been fully elucidated.

Methods A total of 433 healthy subjects aged 40-69 years (234 men, 199 women) were included in the study. The relationship between obesity-related factors (total fat area, visceral fat area, subcutaneous fat area, waist circumference, and body mass index) and the incidence of reflux erosive esophagitis was investigated. Lifestyle factors and stomach conditions relevant to the onset of erosive esophagitis were also analyzed.

Results The prevalence of reflux erosive esophagitis was $27.2 \%$ (118/433; 106 men, 12 women). Visceral fat area was higher in subjects with erosive esophagitis than in those without $\left(116.6 \mathrm{~cm}^{2}\right.$ vs. $64.9 \mathrm{~cm}^{2}$, respectively). The incidence of erosive esophagitis was higher in subjects with visceral fat obesity (visceral fat area $\left.\geq 100 \mathrm{~cm}^{2}\right)$ than in those without $(61.2 \%$ vs. $12.8 \%$, respectively). Visceral fat obesity had the highest odds ratio (OR) among obesity-related factors. Multivariate analysis showed that visceral fat area was associated with the incidence of erosive esophagitis $(\mathrm{OR}=2.18)$, indicating that it is an independent risk factor for erosive esophagitis. In addition, daily alcohol intake $(\mathrm{OR}=1.54)$, gastric atrophy open type $(\mathrm{OR}=0.29)$, and never-smoking history $(\mathrm{OR}=0.49)$ were also independently associated with the development of erosive esophagitis.

Conclusions Visceral fat obesity is the key risk factor for the development of reflux erosive esophagitis in subjects aged 40-69 years.
\end{abstract}

Keywords Reflux erosive esophagitis · Visceral fat obesity $\cdot$ Visceral fat area $\cdot$ Abdominal computed tomography

Shinya Ohashi

ohashish@kuhp.kyoto-u.ac.jp

1 Preemptive Medicine and Lifestyle Disease Research Center, Kyoto University Hospital, 53 Kawahara-cho, Shogoin, Sakyo-ku, Kyoto 606-8397, Japan

2 Department of Therapeutic Oncology, Graduate School of Medicine, Kyoto University, 54 Kawahara-cho, Shogoin, Sakyo-ku, Kyoto 606-8507, Japan

3 Department of Gastroenterology and Hepatology, Graduate School of Medicine, Kyoto University, 54 Kawahara-cho, Shogoin, Sakyo-ku, Kyoto 606-8507, Japan

4 Department of Real Word Data Research and Development, Graduate School of Medicine, Kyoto University, 54 Kawahara-cho, Shogoin, Sakyo-ku, Kyoto 606-8507, Japan

\section{Introduction}

The prevalence of gastroesophageal reflux disease (GERD) has clearly increased over the past 20 years in Japan [1, 2]. Chronic inflammation because of GERD leads to an increased risk of esophageal adenocarcinoma [3], which is expected to increase in Japan [4]. Therefore, it is desirable to understand further the etiology of GERD and to use this information to establish preventive strategies for GERD and esophageal adenocarcinoma.

The incidence of obesity is also increasing in Japan because of sedentary lifestyles and changes in diet [5]. Obesity is usually associated with an increase in visceral and/ or subcutaneous fat [6]. Individuals with visceral fat accumulation are at particularly high risk for common medical complications, including diabetes and cardiovascular disease 
[7, 8]. Although body mass index (BMI) is used to evaluate obesity [9], BMI does not measure body fat directly [10]. Abdominal computed tomography (CT) scans can measure fat volume directly and quantitatively, thereby allowing the separate analysis of visceral and/or subcutaneous fat volumes $[11,12]$. According to the diagnostic criteria of the Japan Society for the Study of Obesity, individuals with visceral fat area $(V F A) \geq 100 \mathrm{~cm}^{2}$ are diagnosed as visceral fat obese [5]. This criterion is used for risk assessment of obesity-related disorders $[12,13]$.

The relationship between obesity and the incidence of GERD has been evaluated in Japanese populations, and a high BMI has been shown to be an important risk factor for GERD [1, 14]. However, the usefulness of VFA measurement in GERD risk assessment has not been fully elucidated. In this study, we evaluated the relationship between visceral fat obesity as defined by abdominal $\mathrm{CT}$ and the risk of reflux erosive esophagitis in age-specific (40-69 years) healthy Japanese subjects and further assessed the various factors involved in the development of erosive esophagitis.

\section{Methods}

\section{Study design}

The study subjects were 641 adults who visited the Preemptive Medicine and Lifestyle Disease Research Center in Kyoto University Hospital for a medical checkup. This study targeted healthy adults aged 40-69 years, with reference to the defined target ages for lifestyle-related diseases [15]. To eliminate the effects of drugs that may affect the presence or absence of GERD, individuals being treated with proton pump inhibitors (PPIs) or H2-receptor antagonist (H2-blockers) were excluded. To eliminate subjects who were not healthy, individuals who were receiving anticancer treatment or who had underlying illnesses were excluded. To eliminate the effects of drug-mediated mucosal damage, individuals being treated with nonsteroidal anti-inflammatory drugs (NSAIDs) or aspirin were excluded. In addition, individuals who had a history of gastrectomy or other abdominal surgery, and/or individuals for whom data analysis was not possible, were excluded (Fig. 1). Subjects were asked about the presence or absence of heartburn, smoking Brinkman index (BI), smoking status, alcohol consumption volume, and the presence or absence of flushing reaction by alcohol intake.

This study was carried out in accordance with the Declaration of Helsinki and the protocol was approved by the ethics committee of the Kyoto University Hospital (R0619 and R2576). Written informed consent, which indicated that clinical data without individual information would be used for the study, was obtained from all subjects.

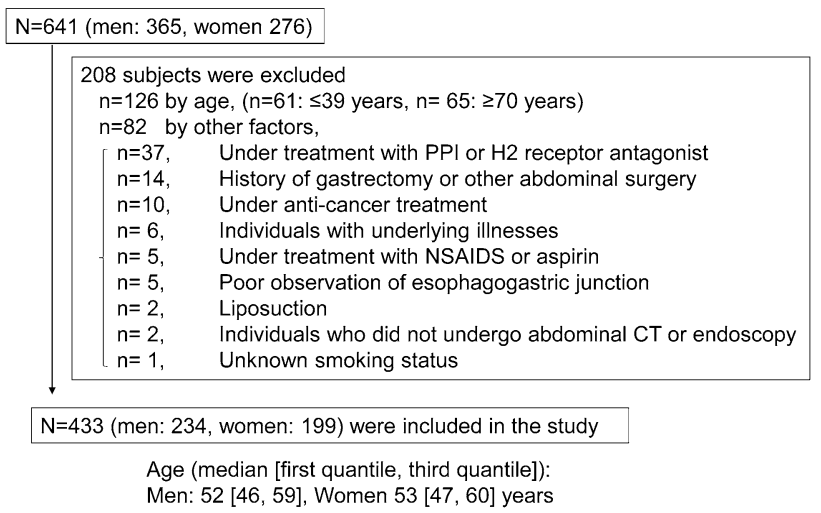

Fig. 1 Subject selection. A total of 641 subjects were received in our facility for a medical checkup from 2017.12 to 2018.6, and 433 (men 234 , women 199) subjects were included in the analysis (208 subjects were excluded by the criteria as described)

\section{Upper gastrointestinal endoscopy}

Reflux erosive esophagitis was diagnosed by mucosal injuries of grade A or worse according to the Los Angeles classification [16]. Esophageal hiatal hernia was defined as apparent separation of the esophagogastric junction and the diaphragm impression at endoscopy by greater than $2 \mathrm{~cm} \mathrm{[17].} \mathrm{Gastric} \mathrm{mucosal} \mathrm{atrophy} \mathrm{was} \mathrm{assessed}$ according to the Kimura-Takemoto classification [18]. Endoscopic images were reviewed by three board-certified endoscopic specialists.

\section{Obesity assessment}

BMI above normal limits was defined as BMI $\geq 25 \mathrm{~kg} /$ $\mathrm{m}^{2}$ [5]. Total fat area (TFA), VFA, subcutaneous fat area (SFA), fat area ratio (VFA/SFA) and waist circumference were obtained from cross sectional CT scans at the level of the umbilicus using an image processing workstation (Ziostation2; Ziosoft Corp, Tokyo, Japan). Individuals with VFA $\geq 100 \mathrm{~cm}^{2}$ were defined as visceral fat obese [5].

\section{Categorization of obesity by VFA and BMI}

In this study, we used the following four categories to classify obesity in subjects: category A. BMI $<25 \mathrm{~kg} /$ $\mathrm{m}^{2}$ and VFA $<100 \mathrm{~cm}^{2}$; category B. BMI $<25 \mathrm{~kg} / \mathrm{m}^{2}$ and VFA $\geq 100 \mathrm{~cm}^{2}$; category C. BMI $\geq 25 \mathrm{~kg} / \mathrm{m}^{2}$ and VFA $<100 \mathrm{~cm}^{2}$; and category D. BMI $\geq 25 \mathrm{~kg} / \mathrm{m}^{2}$ and VFA $\geq 100 \mathrm{~cm}^{2}$. 


\section{Statistical analyses}

Factors associated with the presence or absence of erosive esophagitis were evaluated. Normality of distribution was assessed by Shapiro-Wilk test. The continuous variables that were not normally distributed were expressed as median [first quantile, third quantile]. Univariable analyses were conducted to assess the difference in risk factors between subjects with or without erosive esophagitis. Mann-Whitney $U$ test or Fisher's exact test was used to compare continuous or categorical variables, respectively. The influences of obesity-related factors on the development of erosive esophagitis were estimated by calculating the odds ratios (ORs) and 95\% confidence intervals using logistic regression analysis. For the multivariate analysis, we selected variables based on prior knowledge [19-21] according to the previous key reports on the pathophysiology and epidemiology of GERD [1, 22-25]. Hence, the following eight variables, i.e., sex, obesity (visceral fat obesity and subcutaneous fat obesity), presence of esophageal hiatal sliding hernia, stomach conditions (gastric atrophy open type, and Helicobacter pylori $[\mathrm{H}$. pylori] antibody positivity), and lifestyle factors (average daily alcohol intake and smoking history) were subjected to multivariate analysis. All statistical analyses and visualizations were performed using Microsoft Excel and $\mathrm{R}$ (version 3.6.3) with Rstudio (1.2.5033). R packages, ggVennDiagrama (0.3), officer (0.3.11), cowplot (1.0.0), sf (0.9-6), lawstat (3.4), ggpubr (0.3.0), MASS (7.3-51.5), and tidyverse (1.3.0). Differences at $P<0.05$ were considered statistically significant.

\section{Results}

\section{Subjects}

A total of 208 subjects met the exclusion criteria and were excluded, leaving a total of 433 subjects (234 men and 199 women) for the analysis (Fig. 1). The median ages for men and women were 52 and 53 years, respectively.

\section{Basic characteristics of obesity-related factors by gender}

The median BMI, abdominal diameter, TFA, VFA, and fat area ratio values were significantly higher in men than in women, although there was no difference in the median SFA value. The average serum adiponectin level was significantly lower in men than in women (Table 1).

\section{Diagnosis of erosive esophagitis}

Overall, 118 subjects (106 men, 12 women) were diagnosed with erosive esophagitis, so the prevalence of erosive esophagitis was $27.3 \%$ (118/433, Grade A: 111, B: 7, C: 0, D: 0 ), and all cases of esophagitis in enrolled subjects were mild. The intra-observer concordance rate ( $\kappa$ value) was $82.8 \%$. The prevalence of erosive esophagitis in men was $45.3 \%$ (106/234), whereas that in women was $6.0 \%(12 / 199)$ (Table 2). The prevalence of erosive esophagitis in subjects with heartburn symptoms was significantly higher than in those without (49.0\% [25/51] vs. $24.3 \%$ [93/282], respectively); $22 \%$ of subjects (25/118) with erosive esophagitis had heartburn symptoms.

\section{Comparison of clinical examinations between patients with or without erosive esophagitis}

All obesity-related factors (BMI, TFA, VFA, SFA, fat area ratio, and waist circumference) were significantly higher in subjects with erosive esophagitis than in those without (Fig. 2). As shown in Table 2, serum adiponectin level was significantly lower in subjects with erosive esophagitis than in those without.

Regarding the relationship between visceral fat obesity and the incidence of erosive esophagitis, 61.2\% (79/129) of subjects with visceral fat obesity $\left(\mathrm{VFA} \geq 100 \mathrm{~cm}^{2}\right)$ had
Table 1 Characteristics of participants on obesity indexes by gender

\begin{tabular}{llll}
\hline Obesity indexes & Men & Women & $P$ value \\
\hline Body mass index $\left(\mathrm{BMI}, \mathrm{kg} / \mathrm{m}^{2}\right)$ & $24.6[23.1,26.7]$ & $20.9[19.2,23.5]$ & $<0.001^{\dagger}$ \\
Waist circumference $(\mathrm{cm})$ & $87.4[82.6,92.8]$ & $78.5[72.7,84.2]$ & $<0.001^{\dagger}$ \\
Total fat area $\left(\mathrm{TFA}, \mathrm{cm}^{2}\right)$ & $238.3[195.6,298.2]$ & $195.7[135.6,267.2]$ & $<0.001^{\dagger}$ \\
Visceral fat area $\left(\mathrm{VFA}, \mathrm{cm}^{2}\right)$ & $97.3[68.9,126.8]$ & $45.5[26.0,76.6]$ & $<0.01^{\dagger}$ \\
Subcutaneous fat area $\left(\mathrm{SFA}, \mathrm{cm}^{2}\right)$ & $138.4[108.4,177.3]$ & $149.3[100.3,192.9]$ & $0.47^{\dagger}$ \\
Fat area ratio $(\mathrm{VFA} / \mathrm{SFA})$ & $0.70[0.47,0.90]$ & $0.32[0.24,0.43]$ & $<0.001^{\dagger}$ \\
Serum adiponectin $(\mu \mathrm{g} / \mathrm{mL})$ & $6.4[4.8,8.4]$ & $12.2[8.4,17.1]$ & $<0.001^{\dagger}$ \\
\hline
\end{tabular}

Data are expressed as the median [first quantile, third quantile]

${ }^{\dagger}$ Mann-Whitney $U$ test 
Table 2 Comparison of clinical characteristics between subjects with or without erosive esophagitis

\begin{tabular}{|c|c|c|c|c|}
\hline & $\begin{array}{l}\text { Non-erosive esophagi- } \\
\text { tis }(n=315)\end{array}$ & Erosive esophagitis $(n=118)$ & $P$ value & Percentage \\
\hline Age $(\text { year })^{\mathrm{a}}$ & $52.0[46.5,60.0]$ & $52.0[46.0,59.0]$ & $0.62^{\dagger}$ & \\
\hline Sex & & & $<0.001^{\ddagger}$ & \\
\hline Men & 128 & 106 & & $45.3 \%(106 / 234)$ \\
\hline Women & 187 & 12 & & $6.0 \%(12 / 199)$ \\
\hline Heartburn & & & $<0.001^{\ddagger}$ & \\
\hline$(-)$ & 289 & 93 & & $24.3 \%(93 / 382)$ \\
\hline$(+)$ & 26 & 25 & & $49.0 \%(25 / 51)$ \\
\hline Adiponectin $(\mu \mathrm{g} / \mathrm{mL})^{\mathrm{a}}$ & $9.3[6.4,14.1]$ & $5.8[4.32,8.40]$ & $<0.001^{\dagger}$ & \\
\hline Visceral fat area cut-off $100 \mathrm{~cm}^{2}$ & & & $<0.001^{\ddagger}$ & \\
\hline Non-visceral fat obesity $\left(<100 \mathrm{~cm}^{2}\right)$ & 265 & 39 & & $12.8 \%(39 / 304)$ \\
\hline Visceral fat obesity $\left(\geq 100 \mathrm{~cm}^{2}\right)$ & 50 & 79 & & $61.2 \%(79 / 129)$ \\
\hline BMI cut-off 25 & & & $<0.001^{\ddagger}$ & \\
\hline Non-obesity (BMI < 25) & 250 & 55 & & $18.0 \%(55 / 305)$ \\
\hline Obesity (BMI $\geq 25)$ & 65 & 63 & & $49.2 \%(63 / 128)$ \\
\hline Smoking Brinkman index $(\mathrm{BI})^{\mathrm{a}}$ & $0.0[0.0,390.0]$ & $405.0[100.0,678.8]$ & $<0.001^{\dagger}$ & \\
\hline Smoking status & & & $<0.001^{\ddagger}$ & \\
\hline Current smoker & 52 & 33 & & $38.8 \%(33 / 85)$ \\
\hline Ex-smoker & 107 & 63 & & $37.1 \%(63 / 170)$ \\
\hline Never smoker & 156 & 22 & & $12.3 \%(22 / 178)$ \\
\hline Daily alcohol intake (g/day) ${ }^{\mathrm{a}}$ & $10.0[0.0,40.0]$ & $44.0[15.0,70.0]$ & $<0.001^{\dagger}$ & \\
\hline Flushing reaction by alcohol intake & & & $0.549^{\ddagger}$ & \\
\hline Flushing reaction negative & 179 & 65 & & $26.6 \%(65 / 244)$ \\
\hline Flushing reaction positive & 73 & 24 & & $24.7 \%(24 / 97)$ \\
\hline Flushing reaction unknown & 63 & 29 & & $31.5 \%(29 / 92)$ \\
\hline Anti-H. pylori antibody & & & $0.035^{\ddagger}$ & \\
\hline$(-)$ & 251 & 105 & & $29.5 \%(105 / 356)$ \\
\hline$(+)$ & 64 & 13 & & $16.8 \%(13 / 77)$ \\
\hline Gastric atrophy & & & $0.162^{\ddagger}$ & \\
\hline Closed type & 252 & 102 & & $28.8 \%(102 / 354)$ \\
\hline Open type & 63 & 16 & & $20.2 \%(16 / 79)$ \\
\hline Pepsinogen $\mathrm{I}^{\mathrm{a}}$ & $47.4[38.8,58.2]$ & $51.8[41.8,63.3]$ & $0.04^{\dagger}$ & \\
\hline Pepsinogen II $^{\mathrm{a}}$ & $8.4[6.7,10.1]$ & $8.4[6.9,10.3]$ & $0.85^{\dagger}$ & \\
\hline Pepsinogen $\mathrm{I} / \mathrm{II} \mathrm{ratio}^{\mathrm{a}}$ & $5.8[4.9,6.6]$ & $6.2[5.2,7.0]$ & $0.005^{\dagger}$ & \\
\hline Pepsinogen I/II ratio cut-off 3 & & & $0.02^{\ddagger}$ & \\
\hline$\geq 3$ & 296 & 117 & & $28.3 \%(117 / 413)$ \\
\hline$<3$ (= severe atrophy) & 19 & 1 & & $5.0 \%(1 / 20)$ \\
\hline Esophageal hiatal hernia & & & $<0.001^{\ddagger}$ & \\
\hline$(-)$ & 258 & 35 & & $11.9 \%(35 / 293)$ \\
\hline$(+)$ & 57 & 83 & & $59.2 \%(83 / 140)$ \\
\hline
\end{tabular}

${ }^{a}$ Data for continuous variables are expressed as the median [first quantile, third quantile]

${ }^{\dagger}$ Mann-Whitney $U$ test

${ }^{\ddagger}$ Fisher’s exact test

erosive esophagitis, and $66.9 \%$ (79/118) of subjects with erosive esophagitis were visceral fat obese. Among the subjects without visceral fat obesity, 87\% (265/304) did not have erosive esophagitis.
As for BMI, 49.2\% (63/128) of subjects with high BMI $\left(\geq 25 \mathrm{~kg} / \mathrm{m}^{2}\right)$ had erosive esophagitis, and 53.3\% (63/118) of subjects with erosive esophagitis had a high BMI; $82 \%$ 

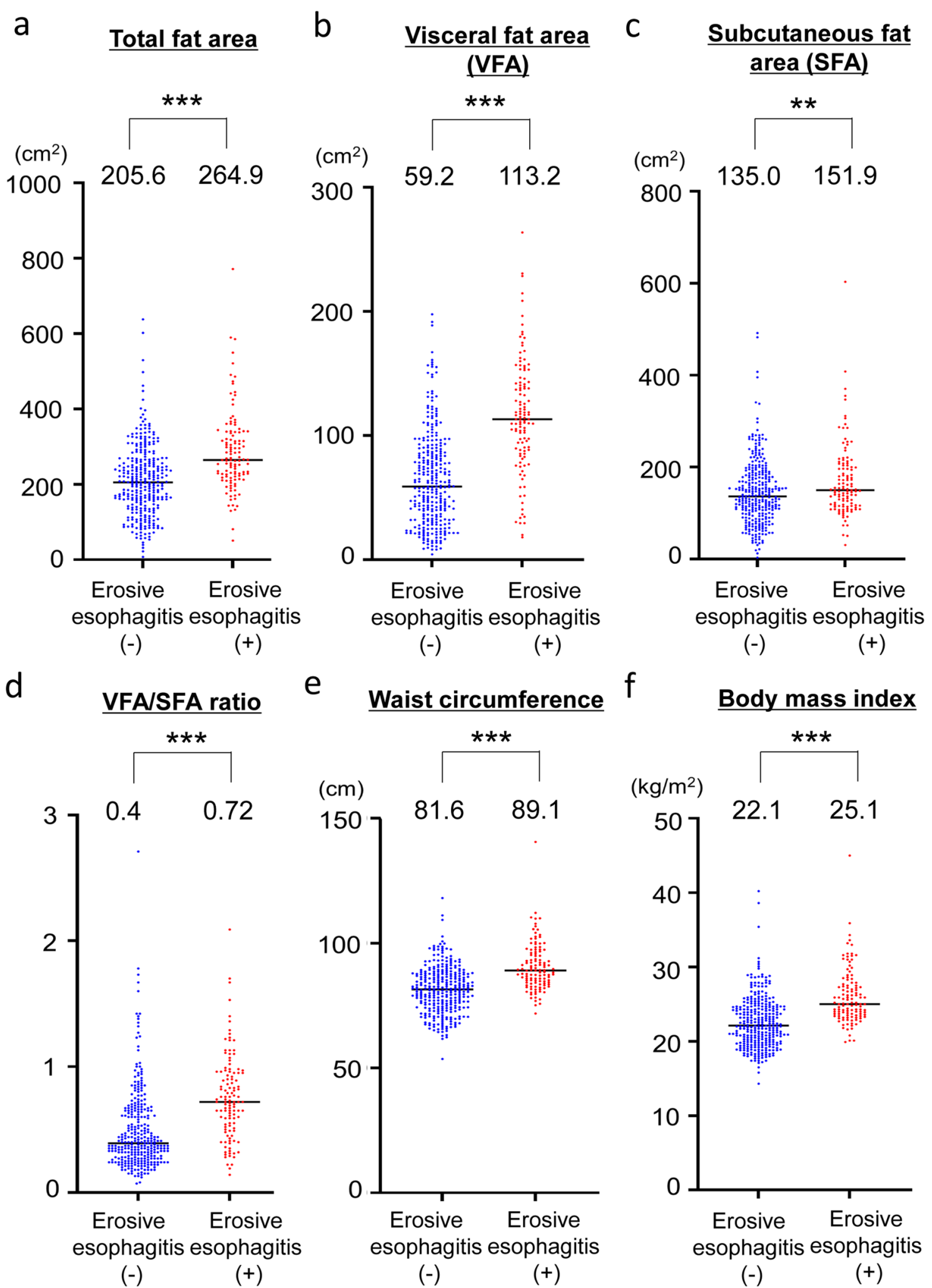

Fig. 2 Comparison of obesity-related factors between subjects with or without erosive esophagitis. a Total fat area, b visceral fat area (VFA), c subcutaneous fat area (SFA), d VFA/SFA ratio, e waist circumference determined by abdominal CT, and $\mathbf{f}$ body mass index (BMI). The median value in each group is indicated. $* * * P<0.001$, $* * P<0.01$ 
$(250 / 305)$ of subjects with normal BMI $\left(<25 \mathrm{~kg} / \mathrm{m}^{2}\right) \mathrm{did}$ not have erosive esophagitis.

Cumulative smoking BI values were significantly higher in subjects with erosive esophagitis than in those without. The prevalence of erosive esophagitis in current smokers, ex-smokers, and never-smokers was 38.8\%, $37.1 \%$, and $18.6 \%$, respectively.

Current daily alcohol consumption was significantly higher in subjects with erosive esophagitis than in those without (44.0 vs. $10.0 \mathrm{~g} /$ day, respectively). The presence or absence of a flushing reaction did not affect the prevalence of erosive esophagitis.

Regarding the relationship between the presence or absence of $H$. pylori antibodies and the incidence of erosive esophagitis, the prevalence of erosive esophagitis was significantly higher in those who were negative for $H$. pylori antibodies (29.5\%) than in those who were positive for $H$. pylori antibodies (16.8\%).

Regarding the relationship between gastric atrophy and the incidence of erosive esophagitis, the prevalence of erosive esophagitis in subjects who were classified into each grade of gastric mucosal atrophy into each category is shown in Online Resource 1. The prevalence of erosive esophagitis in subjects diagnosed with closed type atrophy or open type atrophy was $28.8 \%(102 / 354)$ and $20.2 \%$ (16/79), respectively. The prevalence of erosive esophagitis in subjects with a pepsinogen I/II ratio $\geq 3$ or $<3$, which is the cutoff value to determine severe gastric atrophy [26], was $28.3 \%$ and $5.0 \%$, respectively.

In addition, the prevalence of erosive esophagitis in subjects with esophageal sliding hernia was 59.2\%, whereas that in subjects without esophageal sliding hernia was $11.9 \%$. VFA was significantly higher in subjects with esophageal hernia than in those without $\left(118.1 \mathrm{~cm}^{2}\right.$ vs. $60.2 \mathrm{~cm}^{2}$, respectively, Online Resource 2).

\section{Univariate analysis}

Univariate analysis with continuous variables revealed that BMI, waist circumference, TFA, VFA, SFA, fat area ratio, serum adiponectin level, daily alcohol consumption level, cumulative smoking BI, and pepsinogen I/II ratio were significantly associated with the risk of erosive esophagitis (Table 3 ).

Univariate analysis with non-continuous variables revealed that male gender, VFA $\geq 100 \mathrm{~cm}^{2}, \mathrm{BMI} \geq 25 \mathrm{~kg} /$ $\mathrm{m}^{2}$, heartburn positive, esophageal hiatus hernia positivity, never-smoking history, and H. pylori antibody positivity were associated with the risk of erosive esophagitis (Table 3).

\section{Multivariate analysis}

Male gender (OR 3.36), VFA (OR 2.18), daily alcohol intake (OR 1.54), and esophageal hiatal hernia (OR 3.73) were independent risk factors for erosive esophagitis. Gastric atrophy open type (OR 0.29) and never-smoking history (OR 0.49) were independent negative risk factors for erosive esophagitis (Table 3). The area under the curve (AUC) of the receiver-operating characteristics (ROC) curve calculated from the multivariate analysis was 0.895 (Online Resource 3 ), and the data for the estimated predictive probability are shown in Online Resource 4.

\section{Distribution of visceral fat area by gender in subjects with or without erosive esophagitis}

The median VFA in subjects with erosive esophagitis was significantly higher than that in those without, for both men $\left(115.9 \mathrm{~cm}^{2}\right.$ vs. $79.6 \mathrm{~cm}^{2}$, respectively) and women $\left(97.3 \mathrm{~cm}^{2}\right.$ vs. $43.5 \mathrm{~cm}^{2}$, respectively, Fig. 3a).

\section{Distribution of subjects with erosive esophagitis regarding visceral fat obesity, high alcohol consumption, and gastric atrophy}

Regarding the etiology of reflux erosive esophagitis, we focused particularly on visceral fat obesity, high-level alcohol drinkers, and gastric atrophy (absent or closed type) based on endoscopic findings. As shown, 34 (28.8\%) of 118 subjects with erosive esophagitis had all three factors, and 102 subjects (86.4\%: 102/118) were either visceral fat obese or drinking $\geq 30 \mathrm{~g}$ alcohol/day (Fig. 3b).

\section{Distribution of subjects with erosive esophagitis classified by visceral fat area and BMI}

As shown in Fig. 4, the incidence of erosive esophagitis in each category (A, B, C, D) was $11 \%, 52 \%, 30 \%$, and $65 \%$, respectively.

\section{Discussion}

The increase in the obese population has coincided with a rising prevalence of GERD [22]. Obesity has been shown to be associated with excessive transient lower esophageal sphincter relaxation, which is considered to play a key role in the pathophysiology of the development of GERD because of the increase in intra-gastric pressure [27]. El-Serag, et al. reported that abdominal obesity was correlated with the increase in intragastric pressure, and noted the possible involvement of visceral fat obesity as a mechanism of obesity-mediated intra-gastric pressure elevation [28]. 
Table 3 Effect of obesity on erosive esophagitis by univariate (continuous and/or non-continuous variables) and multivariate analysis

\begin{tabular}{|c|c|c|c|}
\hline Category (continuous variables) & Adjusted OR (95\% CI) & $P$ value & Adjusted coefficient \\
\hline \multicolumn{4}{|l|}{ Univariate analysis } \\
\hline Age & $0.94(0.76-1.17)$ & 0.62 & -0.057 \\
\hline Body mass index (BMI) & $2.83(2.15-3.73)$ & $<0.01$ & 1.04 \\
\hline Waist circumference & $3.02(2.26-4.03)$ & $<0.01$ & 1.11 \\
\hline Total fat area (TFA) & $2.25(1.75-2.89)$ & $<0.01$ & 0.81 \\
\hline Visceral fat area (VFA) & $3.73(2.78-4.99)$ & $<0.01$ & 1.32 \\
\hline Subcutaneous fat area (SFA) & $1.41(1.14-1.74)$ & $<0.01$ & 0.34 \\
\hline Fat area ratio (VFA/SFA) & $2.04(1.62-2.58)$ & $<0.01$ & 0.71 \\
\hline Adiponectin & $0.29(0.2-0.43)$ & $<0.01$ & -1.23 \\
\hline Daily alcohol intake (g/day) & $1.83(1.48-2.27)$ & $<0.01$ & 0.61 \\
\hline Smoking Brinkman Index & $1.94(1.56-2.42)$ & $<0.01$ & 0.66 \\
\hline Pepsinogen I/II ratio & $1.41(1.13-1.76)$ & $<0.01$ & 0.34 \\
\hline Category (non-continuous variables) & OR $(95 \% \mathrm{CI})$ & $P$ value & Coefficient \\
\hline \multicolumn{4}{|l|}{ Univariate analysis } \\
\hline Gender male & $12.9(6.82-24.42)$ & $<0.01$ & 2.56 \\
\hline Visceral fat area $\geq 100 \mathrm{~cm}^{2}$ & $10.74(6.59-17.5)$ & $<0.01$ & 2.37 \\
\hline $\mathrm{BMI} \geq 25 \mathrm{~kg} / \mathrm{m}^{2}$ & $4.41(2.8-6.93)$ & $<0.01$ & 1.48 \\
\hline Heartburn positive & $2.99(1.65-5.43)$ & $<0.01$ & 1.09 \\
\hline Esophageal hiatal hernia positive & $10.73(6.59-17.49)$ & $<0.01$ & 2.37 \\
\hline Never-smoking history & $0.23(0.14-0.39)$ & $<0.01$ & -1.45 \\
\hline Anti-H. pylori antibody positive & $0.49(0.26-0.92)$ & 0.024 & -0.72 \\
\hline Gastric atrophy open type & $0.63(0.35-1.14)$ & 0.12 & -0.47 \\
\hline Flushing reaction positive & $0.91(0.53-1.56)$ & 0.32 & -0.099 \\
\hline Category & OR $(95 \% \mathrm{CI})$ & $P$ value & Coefficient \\
\hline \multicolumn{4}{|l|}{ Multivariate analysis } \\
\hline Gender male & $3.36(1.47-7.67)$ & $<0.01$ & 1.21 \\
\hline Visceral fat area & $2.18(1.45-3.26)$ & $<0.01$ & 0.78 \\
\hline Subcutaneous fat area & $1.26(0.89-1.78)$ & 0.20 & 0.23 \\
\hline Daily alcohol intake (g/day) & $1.54(1.15-2.06)$ & $<0.01$ & 0.43 \\
\hline Gastric atrophy open type & $0.29(0.13-0.66)$ & $<0.01$ & -1.24 \\
\hline Anti-H. pylori antibody positive & $0.44(0.19-1.01)$ & 0.053 & -0.83 \\
\hline Never-smoking history & $0.49(0.25-0.96)$ & 0.039 & -0.72 \\
\hline Esophageal hiatal hernia positive & $3.73(1.99-6.99)$ & $<0.01$ & 1.31 \\
\hline
\end{tabular}

In this study, we demonstrated that visceral fat accumulation was an independent risk factor for the development of erosive esophagitis in subjects aged 40-69 years. Our results are consistent with those of a previous cohort study [23] and case-control studies [24, 29] conducted in South Korea, as well as a cohort study conducted in Japan [25]. Compared with those studies, this study has the following original point: the subjects analyzed in this study were of a specific age group (40-69 years) in which the prevalence of lifestyle-related diseases increases. In addition, we excluded subjects who were taking medications (e.g., PPI/H2-blocker, NSAIDS/aspirin, and anticancer treatment). We believe that the relationship between visceral fat obesity and reflux erosive esophagitis can be accurately evaluated by excluding other factors that may influence the development of erosive esophagitis. Another original point is that we categorized obesity using VFA and BMI, and analyzed the incidence of erosive esophagitis in each category.

In this study, visceral fat obesity had the highest OR among obesity-related factors. In addition, our original categorization regarding obesity demonstrated a high incidence of erosive esophagitis in Categories $\mathrm{B}(\mathrm{VFA} \geq 100$ $\mathrm{cm}^{2}$, and $\left.\mathrm{BMI}<25 \mathrm{~kg} / \mathrm{m}^{2}\right)$ and $\mathrm{D}\left(\mathrm{VFA} \geq 100 \mathrm{~cm}^{2}\right.$, and $\mathrm{BMI} \geq 25 \mathrm{~kg} / \mathrm{m}^{2}$ ). It is an important finding that individuals in Category B, which is not identified as a high-risk group by traditional obesity criteria $\left(\mathrm{BMI} \geq 25 \mathrm{~kg} / \mathrm{m}^{2}\right.$ ), are also at high risk of reflux erosive esophagitis. The mechanism by which visceral fat obesity increases the incidence of 
Fig. 3 Distribution of subjects with or without erosive esophagitis based on visceral fat area by sex, and of subjects with erosive esophagitis based on three factors: visceral fat obesity, high alcohol consumption ( $\geq 30 \mathrm{~g} /$ day), and gastric atrophy absent or closed type. a Box plot showing the distribution of subjects with or without erosive esophagitis on visceral fat area in men and women. $* * * P<0.001$ between groups. b Venn diagram showing the relationship between the three factors and subjects with erosive esophagitis. The number of subjects applicable to each section is indicated. Color code is shown according to the ratio

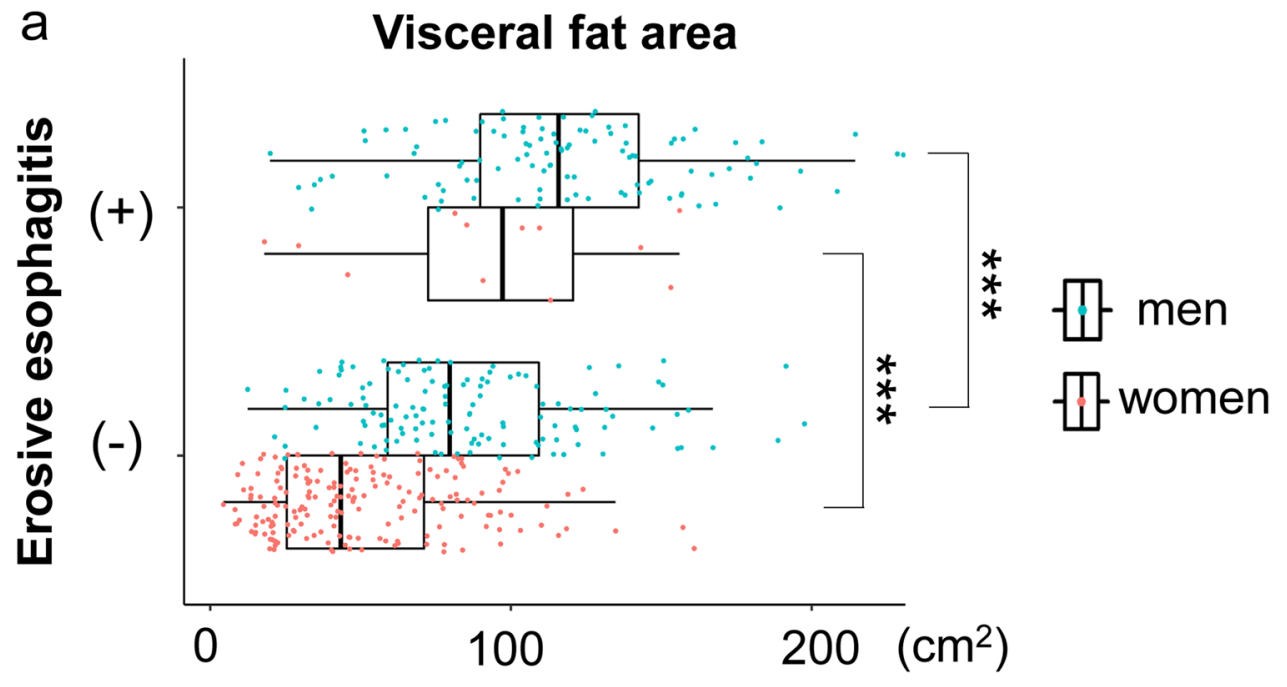

b Erosive esophagitis $(n=118)$

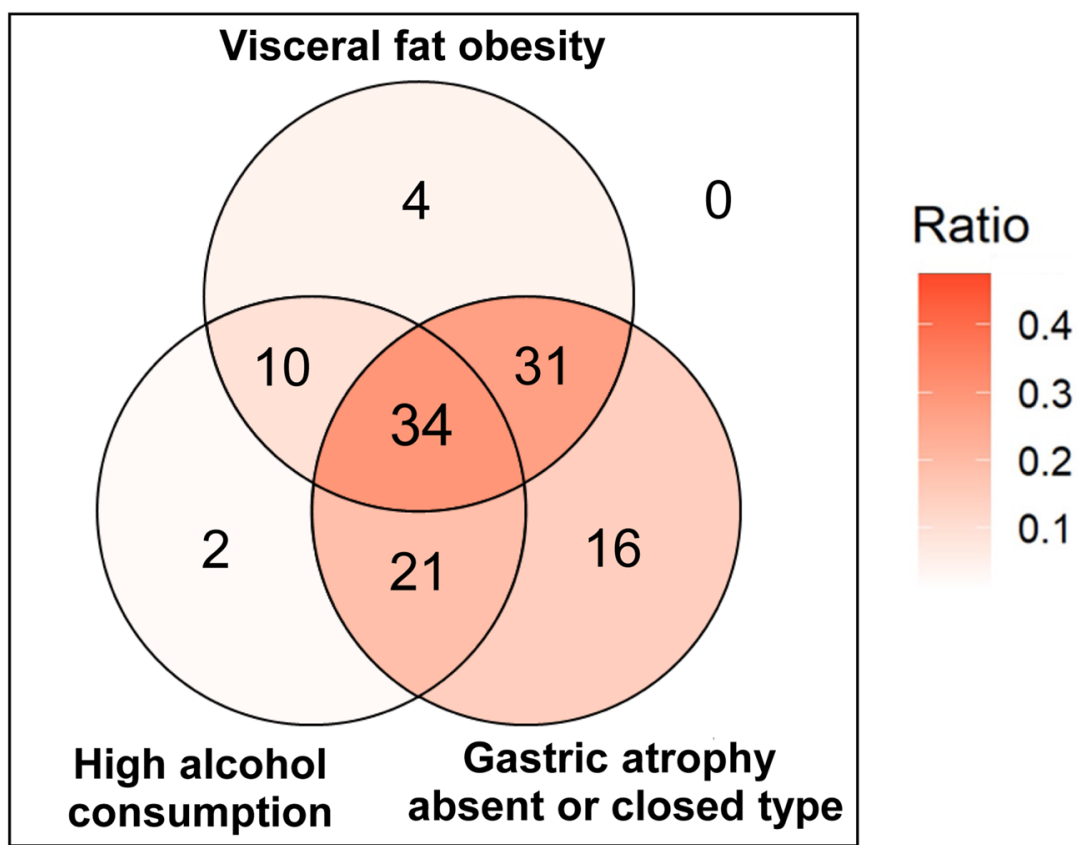

reflux esophagitis most likely involves an increase in intraabdominal pressure, because this increases esophageal acid exposure [30]. In addition, our results support the concept that visceral fat obesity might be involved in the development of esophageal hernia and the subsequent onset of reflux erosive esophagitis.

Further, we showed that serum adiponectin levels were significantly lower in subjects with erosive esophagitis than in those without, which is consistent with a previous report [31]. The circulating adiponectin level is inversely related to visceral fat accumulation [32]. Accordingly, this result supports our finding that visceral fat obesity is associated with the development of reflux erosive esophagitis.
As for gastric condition, we showed that gastric atrophy open type was an independent negative risk factor for the development of erosive esophagitis. Our data also showed that the incidence of erosive esophagitis in subjects with a pepsinogen I/II ratio $<3.0$, which indicates severe atrophy [26], was low compared with that in subjects with a pepsinogen I/II ratio $\geq 3.0$. This finding supports the idea that gastric atrophy is a negative risk factor for the development of erosive esophagitis.

In this study, we focused on the following three factors, visceral fat obesity, high alcohol intake ( $\geq 30 \mathrm{~g} /$ day), and gastric atrophy absence or closed type, as the key for developing reflux erosive esophagitis, because visceral fat obesity 
Fig. 4 Representative abdominal CT images of four subjects according to body fat composition and the distribution of participants in each category. a Abdominal CT images of four cases representing four categories (A, B, C, and D) classified by visceral fat area and BMI. (A) BMI $<25$, visceral fat area (VFA) $<100$ $\mathrm{cm}^{2}$; (B) $\mathrm{BMI}<25, \mathrm{VFA} \geq 100$ $\mathrm{cm}^{2}$; (C) $\mathrm{BMI} \geq 25, \mathrm{VFA}<100$ $\mathrm{cm}^{2}$; (D) $\mathrm{BMI} \geq 25, \mathrm{VFA} \geq 100$ $\mathrm{cm}^{2}$. b Distribution of subjects with erosive esophagitis in four categories. Positive rate of subjects with erosive esophagitis in each category is shown: (A) $11 \%$ [28/262]; (B) 52\% [27/52]; (C) $30 \%$ [12/40]; and (D) $65 \%$ [51/79] a

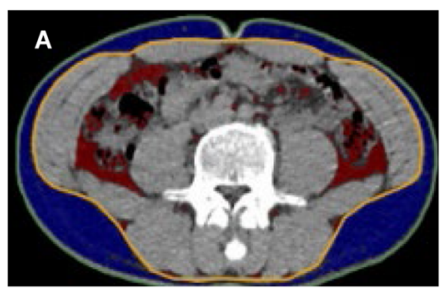

$B M I<25 \mathrm{~kg} / \mathrm{m}^{2}$ and $V F A<100 \mathrm{~cm}^{2}$ : Case: BMI 22.1,

VFA $19.8 \mathrm{~cm}^{2}$, SFA $58.4 \mathrm{~cm}^{2}$

Waist circumference: $71.3 \mathrm{~cm}$

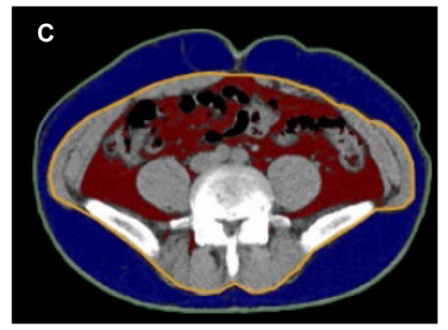

$B M I \geq 25 \mathrm{~kg} / \mathrm{m}^{2}$ and VFA $<100 \mathrm{~cm}^{2}$ : Case: BMI 26.1,

VFA $71.5 \mathrm{~cm}^{2}$, SFA $155.1 \mathrm{~cm}^{2}$

Waist circumference: $83.6 \mathrm{~cm}$

b

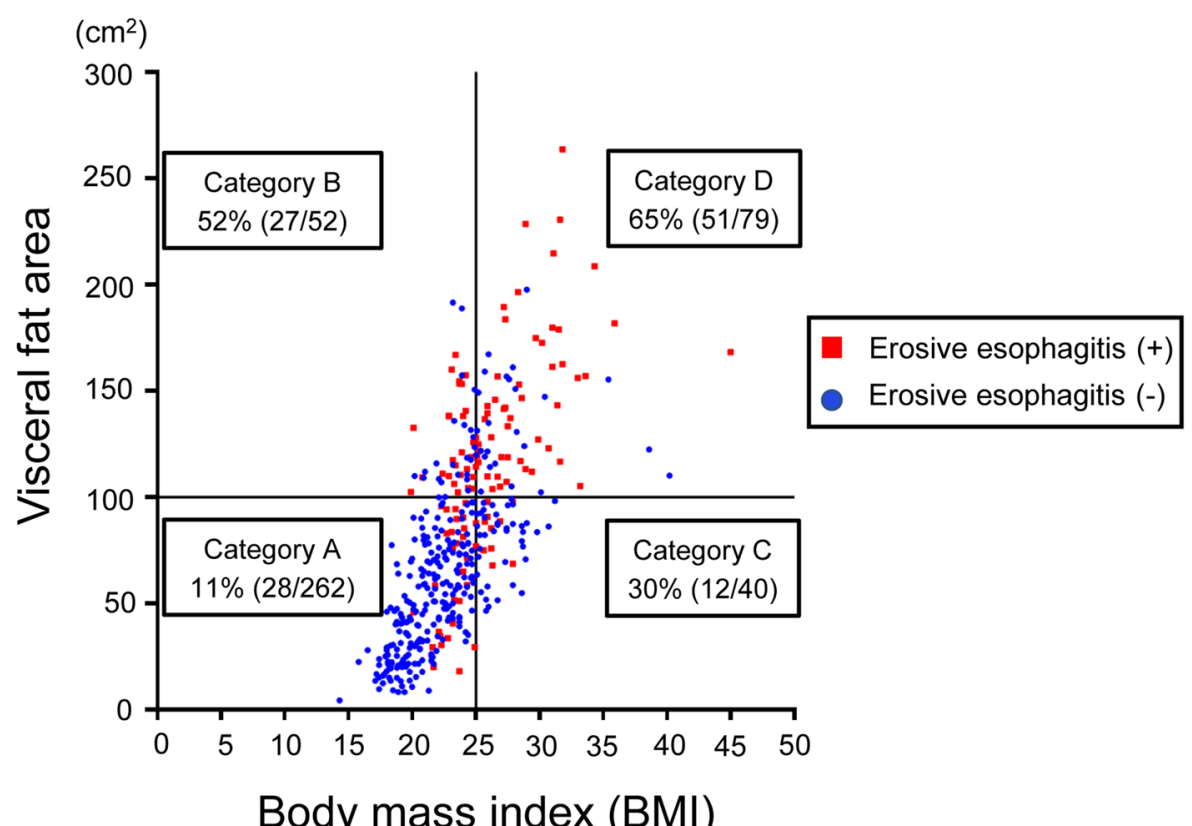

Body mass index (BMI)

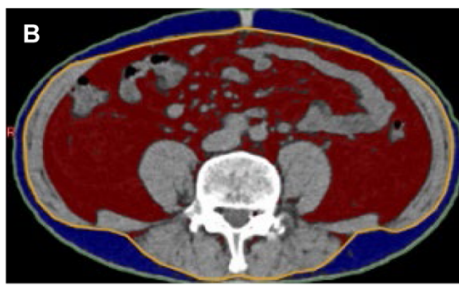

$B M I<25 \mathrm{~kg} / \mathrm{m}^{2}$ and VFA $\geq 100 \mathrm{~cm}^{2}$ : Case: BMI 20.8,

VFA $155.8 \mathrm{~cm}^{2}$, SFA $47.7 \mathrm{~cm}^{2}$

Waist circumference: $77.7 \mathrm{~cm}$

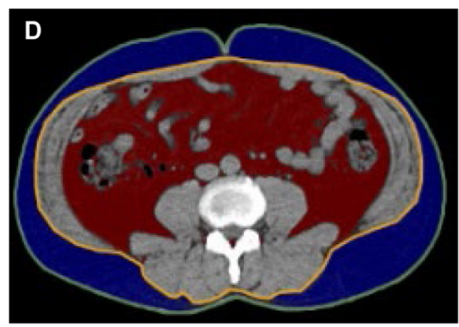

$B M I \geq 25 \mathrm{~kg} / \mathrm{m}^{2}$ and $V F A \geq 100 \mathrm{~cm}^{2}$ :

Case: BMI 27.1,

VFA $191.47 \mathrm{~cm}^{2}$, SFA $164.7 \mathrm{~cm}^{2}$,

Waist circumference: $97.7 \mathrm{~cm}$ and daily alcohol intake were independent positive risk factors and gastric atrophy open type was a negative risk factor for erosive esophagitis. Of note, the proportion of subjects with at least one factor was $100 \%$ (118/118). We speculate that these three factors are key to understanding the pathophysiology of reflux erosive esophagitis in this age group (40-69 years).

In this study, the AUC of the ROC calculated from the multivariate analysis of subjects 40-69 years of age was 0.895 (Online Resource 3). When we evaluated whether the factors that were identified as independent risk factors for the analysis could be applied to younger ( $\leq 39$ years of age $[n=52])$ and older populations $(\geq 70$ years of age $[n=40])$, the AUC of the ROC was 0.892 and 0.879 , respectively (data not shown). Thus, the predictive performance of these risk factors for both the younger ( $\leq 39$ years) and the older ( $\geq 70$ years) groups was similar to that for the group aged 40-69 years. However, we speculate that the predictive performance may decline in patients with underlying illness and/or older patients with osteoporosis and kyphosis. Nevertheless, our analysis may contribute greatly to the prediction of the onset of erosive esophagitis in healthy subjects 
aged 40-69 years, which is the predominant age group for lifestyle-related diseases.

One limitation of the study is that only healthy subjects were enrolled. Therefore, there may be differences in the etiology of GERD between patients and healthy subjects. In addition, the characteristics and the incidence of GERD in our subjects may differ from those in the general population, because this was a single-center study. Issues such as the low incidence of erosive esophagitis in women and the possibility of a selection bias of enrolled healthy populations are also limitations of this study. Further, the relationship between GERD risk and the changes over time in individual visceral fat volume is unclear because this was a cross-sectional study. In addition, the relationship of visceral fat obesity to the severity of erosive esophagitis cannot be evaluated, because all subjects with erosive esophagitis in this study had mild disease. Therefore, visceral fat obesity is an independent risk factor for mild erosive esophagitis, but it remains to be confirmed whether it is associated with the development of severe erosive esophagitis.

In conclusion, we demonstrated that visceral fat obesity is the key independent risk factor for the development of reflux erosive esophagitis. Our findings provide new insights into the etiology of reflux esophagitis and contribute to the establishment of preventive strategies for reflux erosive esophagitis in subjects aged 40-69 years.

Supplementary Information The online version contains supplementary material available at https://doi.org/10.1007/s10388-021-00859-5.

Funding This project was supported by Medical Corporation Midtown Clinic.

\section{Declarations}

Ethical Statement S.O., T.M., S.I., A.M., K.S., F.U., M.Y., H.I., and M.I. are, and A.Y., were, affiliated with the Preemptive Medicine and Lifestyle Disease Research Center of Kyoto University Hospital, which is funded by Medical Corporation Midtown Clinic. The funding source had no role in the design, practice, or analysis of this study.

Conflict of interest S.O., T.M., S.I., A.M., K.S., F.U., M.Y., A.Y., H.I., and M.I. received a research grant from Medical Corporation Midtown Clinic. O.K. and T.S are employed by Medical Corporation Midtown Clinic. K.F., Y.K., S.M., H.S., and M.M declare that they have no conflict of interest.

Open Access This article is licensed under a Creative Commons Attribution 4.0 International License, which permits use, sharing, adaptation, distribution and reproduction in any medium or format, as long as you give appropriate credit to the original author(s) and the source, provide a link to the Creative Commons licence, and indicate if changes were made. The images or other third party material in this article are included in the article's Creative Commons licence, unless indicated otherwise in a credit line to the material. If material is not included in the article's Creative Commons licence and your intended use is not permitted by statutory regulation or exceeds the permitted use, you will need to obtain permission directly from the copyright holder. To view a copy of this licence, visit http://creativecommons.org/licenses/by/4.0/.

\section{References}

1. Fujiwara Y, Arakawa T. Epidemiology and clinical characteristics of GERD in the Japanese population. J Gastroenterol. 2009;44:518-34.

2. Iwakiri K, Kinoshita Y, Habu Y, et al. Evidence-based clinical practice guidelines for gastroesophageal reflux disease 2015. J Gastroenterol. 2016;51:751-67.

3. Lagergren J, Bergström R, Lindgren A, et al. Symptomatic gastroesophageal reflux as a risk factor for esophageal adenocarcinoma. N Engl J Med. 1999;340:825-31.

4. Koizumi S, Motoyama S, Iijima K. Is the incidence of esophageal adenocarcinoma increasing in Japan? Trends from the data of a hospital-based registration system in Akita Prefecture. Japan J Gastroenterol. 2018;53:827-33.

5. The Examination Committee of Criteria for 'Obesity Disease' in Japan, Japan Society for the Study of Obesity. New criteria for 'Obesity Disease' in Japan. Circ J. 2002;66:987-92.

6. Gesta S, Blüher M, Yamamoto Y, et al. Evidence for a role of developmental genes in the origin of obesity and body fat distribution. Proc Natl Acad Sci USA. 2006;103:6676-81.

7. Tirosh A, Shai I, Afek A, et al. Adolescent BMI trajectory and risk of diabetes versus coronary disease. N Engl J Med. 2011;364:1315-25.

8. Dai H, Alsalhe TA, Chalghaf N, et al. The global burden of disease attributable to high body mass index in 195 countries and territories, 1990-2017: an analysis of the Global Burden of Disease Study. PLoS Med. 2020;17:e1003198.

9. Garrow JS, Webster J. Quetelet's index (W/H2) as a measure of fatness. Int J Obes. 1985;9:147-53.

10. Dalili D, Bazzocchi A, Dalili DE, et al. The role of body composition assessment in obesity and eating disorders. Eur J Radiol. 2020;131:109227.

11. Tokunaga $\mathrm{K}$, Matsuzawa $\mathrm{Y}$, Ishikawa $\mathrm{K}$, et al. A novel technique for the determination of body fat by computed tomography. Int $\mathrm{J}$ Obes. 1983;7:437-45.

12. Ryo M, Kishida K, Nakamura T, et al. Clinical significance of visceral adiposity assessed by computed tomography: a Japanese perspective. World J Radiol. 2014;6:409-16.

13. Shah RV, Murthy VL, Abbasi SA, et al. Visceral adiposity and the risk of metabolic syndrome across body mass index: the MESA Study. JACC Cardiovasc Imaging. 2014;7:1221-35.

14. Sakaguchi M, Oka H, Hashimoto T, et al. Obesity as a risk factor for GERD in Japan. J Gastroenterol. 2008;43:57-62.

15. Svensson T, Inoue M, Saito E, et al. The association between habitual sleep duration and mortality according to sex and age: the Japan public health center-based prospective study. J Epidemiol. 2021;31:109-118.

16. Armstrong D, Bennett JR, Blum AL, et al. The endoscopic assessment of esophagitis: a progress report on observer agreement. Gastroenterology. 1996;111:85-92.

17. Iwakiri K, Tanaka Y, Hayashi Y, et al. Association between reflux esophagitis and/or hiatus hernia and gastric mucosal atrophy level in Japan. J Gastroenterol Hepatol. 2007;22:2212-6.

18. Kimura K, Takemoto T. An endoscopic recognition of the atrophic border and its significance in chronic gastritis. Endoscopy. 1969;1:87-97.

19. Greenland S. Modelling and variable selection in epidemiologic analysis. Am J Public Health. 1989;79:340-9. 
20. Walter S, Tiemeier H. Variable selection: current practice in epidemiological studies. Eur J Epidemiol. 2009;24:733-6.

21. Talbot S, Massamba VK. A descriptive review of variable selection methods in four epidemiologic journals: there is still room for improvement. Eur J Epidemiol. 2019;34:725-30.

22. Dent J, El-Serag HB, Wallander MA, et al. Epidemiology of gastro-oesophageal reflux disease: a systematic review. Gut. 2005;54:710-7.

23. Nam SY, Choi IJ, Ryu KH, et al. Abdominal visceral adipose tissue volume is associated with increased risk of erosive esophagitis in men and women. Gastroenterology. 2010;139:1902-1911.e2.

24. Chung SJ, Kim D, Park MJ, et al. Metabolic syndrome and visceral obesity as risk factors for reflux oesophagitis: a crosssectional case-control study of 7078 Koreans undergoing health check-ups. Gut. 2008;57:1360-5.

25. Matsuzaki J, Suzuki H, Kobayakawa M, et al. Association of visceral fat area, smoking, and alcohol consumption with reflux esophagitis and Barrett's Esophagus in Japan. PLoS ONE. 2015;10:e0133865.

26. Kitahara F, Kobayashi K, Sato T, et al. Accuracy of screening for gastric cancer using serum pepsinogen concentrations. Gut. 1999;44:693-7.

27. Wu JC, Mui LM, Cheung CM, et al. Obesity is associated with increased transient lower esophageal sphincter relaxation. Gastroenterology. 2007;132:883-9.
28. El-Serag HB, Tran T, Richardson P, et al. Anthropometric correlates of intragastric pressure. Scand J Gastroenterol. 2006;41:887-91.

29. Lee HL, Eun CS, Lee OY, et al. Association between erosive esophagitis and visceral fat accumulation quantified by abdominal CT scan. J Clin Gastroenterol. 2009;43:240-3.

30. El-Serag HB, Ergun GA, Pandolfino J, et al. Obesity increases oesophageal acid exposure. Gut. 2007;56:749-55.

31. Kato M, Watabe K, Hamasaki T, et al. Association of low serum adiponectin levels with erosive esophagitis in men: an analysis of 2405 subjects undergoing physical check-ups. J Gastroenterol. 2011;46:1361-7.

32. Kishida K, Funahashi T, Shimomura I. Adiponectin as a routine clinical biomarker. Best Pract Res Clin Endocrinol Metab. 2014;28:119-30.

Publisher's Note Springer Nature remains neutral with regard to jurisdictional claims in published maps and institutional affiliations. 